\title{
Social Accountability Pathology in Local Poverty Coping Policy
}

\author{
Rutiana Dwi Wahyunengseh \\ Public Administration, \\ FISIP, Universitas Sebelas Maret \\ Surakarta, Indonesia \\ rutianadwi@staff.uns.ac.id
}

\author{
Budiarjo \\ Public Administration \\ FISIP, Universitas Sebelas Maret \\ Surakarta, Indonesia \\ budiarjo@staff.uns.ac.id
}

\author{
Faizatul Ansoriyah \\ Public Administration \\ FISIP, Universitas Sebelas Maret \\ Surakarta, Indonesia \\ faizatulansoriyah@staff.uns.ac.id
}

\begin{abstract}
This article described the pathological risk arising in relation to the social accountability of poverty alleviation policy. Previous studies found that poverty coping is an area of welfare state model in which the government plays a dominant role as the activator of collaboration between actors to reduce the risk of poor group. The problem to be addressed by this paper was how the implementation of poverty alleviation program often generates friction within society, and biased accountability risk over its policy outcome. This paper aims to explore the problems of poverty coping policy implementation from poverty theory combined with the Multiple Accountability Disorder analysis. The research employed content analysis method on documents of Local Poverty Alleviation Strategy and annually local development program in relation to poverty alleviating for finding the biased accountability that arisen since the policy plan domain. The data were collected using in-depth interview with the LGA in the Tim Koordinasi Penanggulangan Kemiskinan Daerah (Local Poverty Coping Coordination Team) as informants. Interpretive inquiry was used to identify accountability pathology, i.e. the symptoms of comprehension biases towards targeted group and program formulation in the bureaucracy culture and its implications on the public accountability substances. This research found the emergence of elitist pathology risk and information commodification in determining targeted group data. The risk of bureaucratic opportunism pathology was found in determining the contaminated poverty coping activity. Both of them resulted in biased social accountability toward an inclusive local poverty coping policy. This research recommended the publication of poverty indicators transparently to determine the targeted group and the utilization of it in integrated manner between Local Government Agencies as the determinant of poverty alleviation program. Further research was recommended to be conducted on the effect of receiving poverty coping program in group based on the close relationship between targeted group and political actors and apparatus.
\end{abstract}

Keywords-poverty, pathology of social accountability, policy of local government.

\section{INTRODUCTION}

This Government Ordinance No. 63 of 2013 about AreaBased Poverty and Destitution Coping mentions that the attempt of coping poverty aims (i) to fulfill the Basic Need; and (ii) to improve capacity and development of basic ability such as ability of attempting. Idakwoji in Aminu and Onimisi (2014) stated that poverty concept is multidimensional in nature involving economic, social and political phenomena. Economic perspective says that poverty is material deficiency measured from low income, thereby less capable of fulfilling the basic needs. From social view, poverty reflects on low status, less respect socially and vulnerability of being marginalized. From political view, poverty can be seen from inadequate access to political power area and to decision making in allocating public resource.

This study's locus is local poverty. The poverty coping issue is the number one objective of Sustainable Development Goals "to end any forms of poverty". Local poverty coping policy builds on pro-poor budgeting function. Pro-poor budgeting is the development budgeting policy partial to poor people. The pro-poor budget impacts on the improved welfare and the fulfilled need for poor people's basic rights. It pertains to budge politics, that is, the use of power to determine "who receives how much" and "using what mechanism". Therefore, the propoor program assessment identification approach is based on the poverty perspective from social-political point of view [1].

The implementation of poverty coping policy reflects on what become the governments' concern and the change of effect expectedly occurring within society. Poverty alleviation program is generally intended to provide condition improvement in the terms of reducing employment, improving economic productivity, improving education status, improving public health status, and improving housing and settlement environment condition. However, the implementation of poverty alleviation program can improve unsuccessfully the life quality of poor group due to mismanagement, such as less coordination, commitment, and inconsistency, and corruption [2][3]. Poverty alleviation can be failed in improving the 
quality of the poor's life because of: (i) Lack of targeting mechanisms for the poor and the fact that most of the programs do not focus directly on the poor; (ii) Inadequate coordination of the various programs has resulted in each institution carrying out its own activities with resultant duplication of effort and inefficient use of limited resources. Overlapping functions ultimately led to institutional rivalry and conflicts; (iii) Lack of accountability and transparency for making a programs; (iv) lack of involvement of beneficiaries in the formulation and implementation of programs; (v) Absence of target setting for Agencies and programs; (vi) Absence of effective collaboration and complementation among the tiers of government; (vii) Most of the programs lacked mechanisms for their sustainability. The challenge and issue of poverty coping policy is how policy directly copes with directly both the constraints with growth and economic discrepancy consistently in integrated and synergic manner to increase the public's opportunity of improving production capacity and of supporting sustainable productive ability [2][4] [5] [6].

Previous studies focused on the evaluation on the cause of unsuccessful poverty coping program implementation in local area. Poverty coping strategy is determined by the perspectives of policy makers' perspective on the cause of poverty and the dynamic growth of poverty [1][7] [8], [5] [9], [10]. This study will complement previous findings by explaining that there are pathological symptoms behind the unrevealed result of evaluation on the unsuccessful poverty coping policy.

Pathological symptoms can be seen from social accountability point of view. The term pathology is usually used in medical area meaning to study some diseases inherent to human organ resulting in organ dysfunction. Analogically, in social accountability, pathology is defined as a variety of phenomena (symptoms) resulting in social accountability dysfunction. Social accountability dysfunction is counterproductive against democratic values, for example: injustice, budget allocation, majority group's domination, patronage, clientele, corruption, and the similar. Theory used is poverty one combined with public accountability paradox perspective (Harmon, 1995) or mutual accountability disorder (MAD) [11].

Poverty theory explains that poverty coping is depended on the theory used. The individual poverty theory explains that individual's inadequate competency is due to physical limitation, limited competency, and limited access. It leads the social grant to be less helpful in alleviating poverty when the strategy of coping poverty requires reward and punishment compelling the growth of individual's willing and ability of being productive [12][13][14]. Poverty theory also explains that poverty is the result of a series of social-political, cultural and geographical conditions making a group of people marginalized. Poverty culture perspective explains that poor people culture is a belief system and dysfunctional knowledge, opportunistic and non-productive subculture perpetuated from one generation to the next $[15][16][17][10]$. Consequently, this perspective leads the poverty coping program to be oriented to change the society's view and to break the chain of poverty culture transmission to young generation [8][10].
Finally, poverty theory also explains that Poverty Caused by Cumulative and Cyclical Interdependencies. This theory explains interdependence between individual situation and society resource with loose, interrelated, cyclical, and interdependent economy in cumulative causal process. This theory suggests that people becomes less fortunate in their social context, and then affects psychological ability at individual level. Such the condition can be exacerbated with structural and political factors making them more marginalized.

Responsibility paradox [18] is used in this article to explain bias risk in poverty coping strategy. The responsibility paradox explains that when bureaucracy undertakes its duty merely as the responsibility of achieving normative objective as mandated in regulation or political mandates, bureaucrats will not assume the personal responsibility as moral agent of action product they do. Otherwise, when bureaucracy participates actively in determining public objective corresponding to the guidance of personal morality value, it may be considered as breaking the administrative rule or political mandates. It is the paradox of responsibility. Bureaucrats tend to utilize situation to secure its position (Bureaucratic Opportunism). Its implication to poverty coping Strategy is that it can bring about the tendency of policy implementation based on merely procedure or formality.

Pathologies of Accountabilities [11] explains that accountability contains five different concepts as the manifestation of accountability corresponding to the consensus for the interest and the wish of those asking (the accountee) to be accountable. From the MAD concept, biased accountability is due to many aspects of accountability assessment on the accountor. The assessment of accountability can be varied between accountees. Many parties becoming the accountee make what is accountable in one side unaccountable in other side.

The relationship between paradox accountability and poverty theory explains that the poverty coping strategy can result in biased accountability, because bureaucrat deals with many parties asking for accountability. Similarly, the community in power relation with the bureaucrat environment is potentially affected by MAD thereby resulting in biased accountability. Biased accountability in this article is called pathology of accountabilities

\section{METHODS}

This research employed a collective case study with interpretive perspective, to analyze the phenomena of actors' behavior and their view on the practical implementation the poverty coping strategy. The informants of research consisted of (i) 15 persons from 6 Local Agencies (thereafter called LA) affiliated with Local Poverty Coping Coordination Team (TKPKD); (ii) 50 persons from 5 sub districts receiving poverty grant (thereafter called B/ Beneficiaries); (iii) 20 persons from 5 NGOs or members of society related to the advocacy of local poverty alleviation (thereafter called AC/Active Citizenship).

The document becoming data source to be analyzed was the content of policy information in Local Poverty Coping Strategy (thereafter called I/Information). The theme of data analysis was the characteristics of relation of activist citizen to government and citizen in the context of local poverty program 
(thereafter called P/power). The triangulations used in this research were research informant triangulation, by asking the same subject of question to different informants, and data collection triangulation, a topic explored through three methods: in-depth interview, field observation, and document analysis.

The prepositions used as the basic framework of the analysis in this study are constructed from poverty theory assumptions framed with accountability paradox perspective. Referring to the theory, the preposition used as the framework of analysis is formulated as follows:

1. Poverty Coping Policy is influenced by individual ability, social environment, social-cultural environment, and local political policy;

2. Poverty grant gives incentive to reinforce poverty when it is not compensated with sanction mechanism and accountability demand;

3. Utilization of poverty data and information to allocate poverty social grant potentially to strengthen the patronclient relation

4. The implementation of poverty coping policy results in some opportunities of social accountability pathology

\section{RESULT}

Poverty in Surakarta City is defined as the people's inability or limited ability of fulfilling their life needs on minimum margin of economic welfare. Poverty coping policy of Surakarta City is governed with Surakarta Mayor's Ordinance Number $2-\mathrm{H}$ of 2013 about Local Poverty Coping Strategy in Surakarta City. The poverty coping activities are distributed into 43 programs in 11 Local Government Agency: Education, Youth and Sport Service, (ii) Health Service, (iii) Social, Labor, and Transmigration Service, (vi) sub district, (vii) Community Empowerment, Women Empowerment, Child Protection and Family Planning Agency, (viii) Cooperative and SME Service, (ix) Agricultural Service, (x) Market Management Service, and (xi) Industry and Trade Service.

Data of Social Service explains that there are about $20 \%$ poverty grant beneficiaries not fulfilling the criteria of poverty indicator, when it is validated in their home address. Data triangulation conducted in surrounding society (B and AC) explains that during the registration of poor group, some individual groups view it as the opportunity of taking profit. Consequently, the non-poor group having access to registration officer will benefit from this opportunity. It indicates the manifestation of preposition "Poverty grant gives incentive to strengthen poverty when it is not compensated with sanction mechanism or accountability demand".

Document analysis conducted on the evaluation of work tool grant recipient's performance to improve the productive activity of poor group shows that $47 \%$ of them continue their business in one last year since obtaining training and work tool grant. Data triangulation on interview with government (LA), Society Activist (AC), and beneficiary groups (B) explains:

"Some of them resell the work tool given by government because they cannot continue their non-developing business.
Even some of them have never begun their business, as they sold their tools as soon as the training has been completed. Those doing so usually have never operated business and some others often obtain grant as they are designated by irresponsible apparatuses or the ones having connection to political actor".

It indicates the realization of preposition: "Poverty grant gives incentive to strengthen poverty when it is not compensated with sanction mechanism or accountability demand".

Another phenomenon identified from field observation and document analysis on performance report shows that an area receives defecation space aid (thereafter called $M C K=$ Mandi Cuci Kakus) program, but some MCKs no longer function because no one maintains them. Data triangulation on interview with society (B) and kelurahan (village office) officer shows the following information:

"We receive $M C K$ program only, we do not apply for it; they said it is the grant from central government. We find constraint in maintaining it because as usual, it is unclear who is responsible for its maintenance. Having been damaged, an object will be neglected".

This data shows inappropriate support of social-cultural context confirms the preposition: The implementation of poverty coping policy results in some opportunities of social accountability pathology and harms the sustainability of poverty alleviation program.

Analysis on Local Poverty Coping Strategy and Local Apparatus Work Plan Document finds that literally the formulation of activity programs seem to be partial to poverty reduction, but in detailed explanation of activities in Dokumen Pelaksanaan Anggaran (DPA/ Budget implementation document of local government agencies), it can be seen that the budget is allocated more on the funding of program process consumed by bureaucratic apparatus. For example, in Capital Access Reinforcement, Facilitation \& Building of SME, Infrastructure Procurement, Product Marketing Reinforcement programs and activities, with budget proportions of Marketing (24\%), Capital (26\%), Building (38\%), and Infrastructure $(12 \%)$. The component of "building with budget allocation of $38 \%$ " contains honor budget post and administrative cost, the recipient of which is apparatus. In other words, there is elite capture pathological phenomenon of budget use. It indicates the manifestation of preposition that poverty coping strategy policy is affected by individual ability, social-cultural environment, and local political policy.

Interview with poverty grant beneficiary group (B) and FGD with community activist (AC) show that $40 \%$ grant beneficiaries have acquaintance with political party cadres; $40 \%$ with government apparatus; and $20 \%$ obtain information from Neighborhood (Rukun Tetangga) meeting and from fellow citizens. Some informants (B) suggest similarly regarding the source of grant access.

"I got all poverty grant cards, nearly all of people in our complex got it, because we have strong representatives in DPRD (Dewan Perwakilan Rakyat Daerah [Local Legislative Assembly])"

It indicates the preposition: "Utilization of poverty data and information to allocate social poverty grant potentially 
strengthens the patron-client relation".

\section{IV.DISCUSSION}

The problems found in the inclusive poverty coping policy implementation in Surakarta city are as follows. Firstly, there is inappropriate targeted group of poverty help recipient specified by central government, in this case data of Social Protection Program. It can be seen from some groups that must not be poor according to the public receiving poverty aid (grant), and vice versa. This pathology arises on target group determination domain in which chief of Neighborhood Committee tends to input all lists of people name to avoid the complaint from those not receiving the grant. So, the screening of poor people data has contained biased social accountability, bureaucratic opportunism, in which the chief of Neighborhood Committee tends to look for safe way for him. Data of poor people enlisted is not organized based on public participation and not published publicly. When the community complains with the inappropriate targeted group, the government excuses that it has accepted the data in such the way it is from central government. It indicates pathological phenomenon of buck passing, in which the ruler (government or political official) throw its responsibility away when it is asked to be accountable for by the public with an excuse of enacted rule and his limited authority [18][19].

Secondly, there is a planning staff's tendency to develop program and activity by copying-pasting other programs regardless an evaluation on the achievement of previous program outcome's performance. Data of poverty coping program is organized on the central government's imperative to write Local Poverty Coping Implementation Report (Laporan Pelaksanaan Penanggulangan Kemiskinan Daerah, thereafter called LP2KD), and is not correlated with Renja document of Local Government Agency. The planner's tendency is to bring the planning obligation down, regardless whether or not it impacts on the changing poverty condition of people indicating the presence of Atrophy of Personal Responsibility pathological symptom, in which the planning staff shrinkages personal responsibility with an excuse that apparatus only undertakes routine duty. So, public accountability is shifted to the responsibility of undertaking formal duty according to description of organizational/bureaucratic duties [18].

Thirdly, it is due to the public's tendency to consider that they are poor in order to get aid (grant). This tendency meets patron-client climate, resulting in comodification of poverty data. The case evidence can be seen from Civil Servants (PNS) enlisted as the recipients of jamkesmas (Public Health Insurance), while they are not deserve to receive it, because the insurance should be given to the have-not community. In another case, some people obtain more training and capital grant from the group with close relationship to political party or government apparatus. It indicates the presence of patronage, clientele, and favoritism phenomena, i.e. the group having a close relationship to government has privilege.

Fourthly, it pertains to the sustainability of poverty coping program. Most programs/activities are temporary and artificial in nature, thereby not touching the substance of poverty causing issue. It explains the preposition that individual ability, social-cultural environment, and local political policy determines the effectiveness of poverty coping program.

Fifthly, the problem pertains to the low opportunity of program sustainability due to the community's low awareness of developing independency in continuing the program assigned by the government. This phenomenon indicates pathological symptom of public need commodification, meaning public need as a commodity to attract the public fund issuance

\section{CCONCLUSION}

This research finds some prepositions. Firstly, poverty Coping Policy is affected by individual ability, social-cultural environment, and local political policy. The same intervention with poverty coping policy will result in different change level in different groups.

Secondly, poverty grant gives incentive to confirm poverty when it is not compensated with sanction mechanism or accountability demand. In the group tending to take shortcut and having poor spirit of independence, poverty grant will strengthen the culture of being dependent on government's grant.

Thirdly, Utilization of poverty data and information to allocate social poverty grant potentially strengthens the patronclient relation. Certain group feels happy and wants more grants in the form of cash. The groups having close relationship with political actor tend to get more access to poverty coping program.

Fourthly, the implementation of poverty coping policy results in some potential pathologies of social accountability. Pathological phenomenon leading to a biased utilization of poverty coping program results from both government and public domains. From government domain, it is triggered by procedural formalistic culture triggering the emergence of: (i) bureaucratic opportunism pathology, (ii) buck-passing pathological symptom, (iii) Atrophy of Personal Responsibility, and (iv) budget using elite capture pathological symptoms. From public domain, it is triggered with comodification culture triggering the emergence of: (i) comodification of poverty data, (ii) patronage, clientele, favoritism phenomenon, and (iii) public need comodification pathological symptom.

Practical recommendation given to the implementation of poverty coping policy is as follows. Firstly, integrative data organized from public participation to be implemented through public test to Neighborhood Level. Secondly indicator of assessor to determine the targeted recipient group criterion of poverty program should be published transparently through various media, thereby opening the opportunity of access to community-based monitoring and public control. Thirdly, data of poor family-targeted group screening should be transparent to get public conformation and validation directly. Fourthly, there should be an improvement of public grievance reporting system through the improved effectiveness of Community Grievance Post (thereafter called Posdumas) at kelurahan and kecamatan (subdistrict) levels.

The recommendation for further research is based the preposition that cultural and structural factors serve as the important element determining the successful inclusive poverty 
coping strategy that is not temporary but permanent and sustainable. This research recommends a study to be conducted on the effect of poverty coping program receiving on the groups having close relation with political party cadres and those having no close relationship with them. The study is expected to give information about the extent to which the preposition formulated in this research "Utilization of poverty data and information to allocate social poverty grant potentially strengthens the patron-client relation" has been actualized.

\section{REFERENCES}

[1] A. J. Lehning MSS, "Political Science Perspectives on Poverty" in Journal of Human Behavior in the Social Environment, 16:1-2, 2007, pp. 87-103, DOI: 10.1300/J137v16n01_07

[2] I. Muo, "Poverty: The Challenges, The Imperatives" in Zenith Economic Quarterly. 2 (12) September, 2007.

[3] B. Anger, 2000, "Poverty Eradication, Millennium Development Goals and Sustainable Development in Nigeria" in Journal of Sustainable Development Vol. 3 No. 4 pp 138-141, 2000

[4] M.I.Obadan, Poverty Reduction in Nigeria: The Way Forward in CBN Economic and Financial Review, Vol. 39, No.4, 2001

[5] A.G., Moges, "Economic Growth, Inequality and Poverty in Developing Countries: Policy Issues and Challenges" in The International Journal of Economic Policy Studies, Volume 8, 2013, pp.41-66.

[6] J. O. Nkwede, "Approaches for Poverty Alleviation and Sustainable Development in Nigeria: A Study of Ebonyi State Community Based Poverty Reduction Agency (EB-CPRA)" in International Journal of Social Science Studies Vol. 2, No. 1; January 2014, ISSN 2324-8033 E-ISSN 2324-8041, Redfame Publishing URL: http://ijsss.redfame.com

[7] M. Sameti, R.D Esfahani, H.K. Haghighi, "Theories of Poverty: A Comparative Analysis" in Kuwait Chapter of Arabian Journal of Business and Management Review Vol. 1, No.6; February 2012, pp. 45-56.

[8] K. D. Kessey, " Global poverty reduction policy and implementation strategies at local level, integrated planning options and challenges in a developing country, Ghana" in Merit Research Journal of Art, Social Science and Humanities (ISSN: 2350-2258) Vol. 1(6) pp. 076-085, October, 2013

[9] I. Aminu and T. Onimisi, T., "Policy Implementation and The Challenges of Poverty Alleviation in Nigeria" in Academic Journal of Interdisciplinary Studies, Vol. 3 No 4, July 2014 Rome-Italy, MCSER Publishing, ISSN 2281-3993, E-ISSN 2281-4612, 2014, p.295-300.

[10] J. Sanberg, 2015, "Evidence-based Policymaking? Revisiting the "Known," the Assumed and the Promoted in New Social Development Policy" in Journal of Poverty Alleviation and International Development, 6(2), the Institute for Poverty Alleviation and International Development, 2015

[11] J. Koppell,"Pathologies of accountability" in Public Administration Review, 65(1),2005, pp. 94-108.

[12] J. Maskovsky, "Afterword: Beyond the privatist consensus" in J. Goode, \& J. Maskovsky (eds), The new poverty studies . New York: New York University Press, 2001.

[13] S. A.Levitan, G. L Mangum, S. L Mangum, \& A. M. Sum, Programs in Aid of the Poor. Baltimore: Johns Hopkins University Press, 2003.

[14] D. Campbell \& J. Wright. Rethinking Welfare School Attendance Policies. Social Service Review, 79(1), 2005, 2-28.

[15] T.J.Sugrue, "The Impoverished Politics of Poverty in Yale Journal of Law \& the Humanities: Vol. 6: Iss. 1, 1994, Article 15.
[16] E. G. Goetz, Clearign the Way: Deconcentrating the Poor. Washington DC: Urban Institute Press, 2003

[17] J. Goering, J. D Jeins, \& T. M. Richardson, "What have we learned about housing mobility and poverty deconcentrration" in J. Goering, \& J. D. Feins (eds), CHoosing a better life? Evaluating the moving to opportunity social experiment (pp. 3-36). Washington DC: Urban Institute Press, 2003

[18] M.M, Harmon, Responsibility as Paradox: A Critique of Rational Discourse on Government, Thousand Oaks, CA: Sage, 221, 1995.

[19] N.C. Roberts, "Keeping Public Officials Accountable through Dialogue: Resolving the Accountability Paradox in Public Administration Review, Vol. 62, No. 6 (November-December), pp. 658-669, Thousand Oaks, CA Sage Publications, 2002. 